\title{
Maternal tactics for mitigating neonate predation risk during the postpartum period in Thomson's gazelle
}

\author{
Blair A. Roberts and Daniel I. Rubenstein \\ Department of Ecology and Evolutionary Biology, Princeton University \\ Princeton, NJ 08540, USA \\ Published in Behavior vol 151 p 1229-1258
}

\begin{abstract}
The time immediately following birth is a period of high predation risk for ungulate neonates. Ungulate mothers exhibit perinatal behaviors that appear to mitigate offspring risk during this time. However, few studies of infant mortality include the postpartum period. Therefore, the function and effectiveness of these maternal behaviors are untested. We observed perinatal behavior in 11 Thomson's gazelle (Eudorcas thomsonii) mother-infant pairs in a free-ranging population under predaiton pressure. Five of the six fawns that were detected by predators during the perinatal period were killed. Fawn survival therefore depended on avoiding detection by predators. Considered individually, neither prepartum isolation from conspecifics nor birth site selection affected the risk of being detected by a predator. However, analyses revealed two distinct perinatal tactics: mothers either isolated and gave birth in tall grass or remained in their social groups and gave birth in short grass. Both of these tactics resulted in lower risk of predator detection compared to behavior that was inconsistent with either tactic. The tactics represent a maternal trade-off between minimizing the duration of the highly vulnerable postpartum period and minimizing conspicuousness to predators.
\end{abstract}

\section{Keywords}

parturition, Eudorcas thomsonii, Thomson's gazelle, maternal care, infant mortality, predation, ungulate, postpartum period

\section{Introduction}

Ungulates, like most mammals, experience their highest mortality risk during infancy (Caughley, 1966). Where predators are present predation is the primary threat to offspring survival (Linnell et al., 1995; Rubenstein \& Nuñez, 2009). Each species uses one of two main strategies, following or hiding, to mitigate offspring predation risk. Follower infants accompany their mothers continuously from birth and rely on flight and maternal defense to escape attacking predators (Walther, 1965; Lent, 1974). Hider infants spend the majority of their time lying motionless in vegetation apart from their mothers, who return several times per day to care for their young. Both strategies are effective at protecting ungulate offspring (Walther, 1965; Lent, 1974). However, neither strategy can be implemented during the period immediately after birth, known as the postpartum period (Lent, 1974).
The postpartum period is perhaps the most vulnerable time of an ungulate's life. Ungulates are born unable to stand, walk or run and are coated in odiferous birth materials that hinder their movements and attract predators (Leuthold, 1977; Roberts, 2012a, b). Furthermore, they are unable to recognize their mothers, who themselves have not yet bonded to or learned to recognize their offspring (Lent, 1974; Estes \& Estes, 1979). During the postpartum period, the mother and infant must efficiently rectify these conditions so that the neonate may engage in and benefit from the hiding or following strategy. Until hiding or following begins, the neonate's safety depends on the behavior of its mother and the conditions under which she has chosen to give birth.

In many ungulate species, parturient females seem to mitigate neonate risk during the postpartum period by controlling the ecological and social context in which parturition occurs. 
Ungulate mothers often select protective habitats in which to give birth in order to minimize the risk of a predator encountering the neonate. However, what constitutes a protective habitat varies by species: some species select birth sites with concealing vegetation (Gosling, 1969; Jarman, 1976; Leuthold, 1977) while others prefer habitats with high visibility (Poole et al., 2007; Rearden et al., 2011; Pinard et al., 2012) or low predator density (Bergerud et al., 1984; Alados \& Escos, 1988; Festa-Bianchet, 1988). In gregarious species, birth site selection is often accompanied by isolation from social groups (Fraser, 1968; Gosling, 1969; Jarman, 1976; Leuthold, 1977; Guinness et al., 1979; Byers, 1997). Isolation is thought to reduce non-predatory disturbances such as sexual harassment or aggression by conspecifics (Gosling, 1969; Lent, 1974; Estes \& Estes, 1979; Guinness et al., 1979), which can result in injury or failure of the mother and infant to bond appropriately and increase predation risk by delaying the onset of following or hiding (Jarman, 1976; Estes \& Estes, 1979; Read \& Frueh, 1980).

Within species, females may vary in their tendency to exhibit birth site selection and prepartum isolation. For example, Lott \& Galland (1985) found that female bison (Bison bison) are more likely to isolate in wooded habitats compared to open plains. The authors suggest that these behaviors serve to reduce predation risk during parturition: bison females prefer to isolate and give birth in areas with vegetative cover where they and their calves will be less conspicuous to predators, but will use conspecifics for cover when vegetation is unavailable. This second option is less favorable and only used in the absence of vegetative cover because it exposes the mother-calf pair to interferences by conspecifics. The study indicates that species may exhibit multiple conditionally-dependent tactics for reducing neonate predation risk. Major bison predators were absent in Lott \& Galland's (1985) study and no predation at- tempts were observed; therefore, the relative effectiveness of the tactics in preventing predation could not be determined.

To date, no study has provided an integrated investigation of the effects of habitat cover and prepartum isolation on offspring survivorship during the perinatal period. The postpartum period is difficult to predict and observe due to its brevity and the skittishness of parturient females (Fraser, 1968). Studies of ungulate infant mortality, therefore, rely on remote monitoring of infant survival beginning hours or days after birth, once the offspring has already survived the vulnerable postpartum period (e.g., Smith \& Anderson, 1996; Singer et al., 1997; Janermo et al., 2004; Olson et al., 2005; DeVivo et al., 201 1; Buuveibaatar et al., 2013). Information regarding neonate mortality risk and the role of maternal decisions in determining neonate survival during the postpartum period is thus integral to our understanding of ungulate population dynamics.

For this study we observed perinatal behavior and neonate predation events in freeranging Thomson's gazelles (Eudorcas thomsonii), a hider species. Mothers in the study population exhibited variation in their use of perinatal tactics, which enabled us to conduct the first integrated analysis of these behaviors and their effects on neonate survival. Given that gazelle neonates are incapable of fleeing predators, we expect that detection of the fawn by predators will result in predation. If this is true, maternal efforts to prevent offspring predation must prevent detection of the neonate by predators. Although black-backed jackals (Canis mesomelas), the primary fawn predators at our field site, sometimes detect fawns exclusively through olfaction, our observations of this species' hunting behavior suggest that most attacks begin with visual detection of either the fawn itself or its mother. Mothers can be distinguished from non-mothers by their greater tendency to be in tall grass and isolated from conspecifics (Fitzgibbon, 1993). In most attacks, jackals 
either run directly at exposed fawns or identify a likely mother from a distance and then search around her for hidden offspring (Fitzgibbon, 1993; Byers, 1997; B.A.R., personal observation).

Based on Lott \& Galland's (1985) findings in bison, we hypothesize that prepartum isolation and birth site selection do not vary independently, but rather that some combinations of habitat type and social context will be more effective at preventing fawn predation than others, and that these combinations will be favored by parturient females. After determining overall patterns of perinatal tactic use, we examine possible mechanisms by which these behaviors serve to reduce fawn predation risk. Specifically, we test whether isolation from conspecifics prior to birth reduces the occurrence of non-predatory disturbances, thereby minimizing the duration of the postpartum period and reducing the fawn's risk of being detected by predators before hiding commences. We also investigate whether vegetative concealment of the fawn at the birth site affects its risk of detection by predators.

\section{Methods}

\section{Study site}

We conducted all fieldwork at Ol Pejeta Conservancy $(\mathrm{OPG})$ in Laikipia, Kenya. OPG is a fenced, $360 \mathrm{~km}^{2}$ conservancy consisting of discrete grassy plains less than $10 \mathrm{~km}^{2}$ in area separated by Acacia drepanolobium and Euclea divinorum woodlands. Animals on OPG are well-habituated to vehicles; therefore, we were able to approach individuals to distances of approxi-mately 100 to $150 \mathrm{~m}$. At this distance we were able to use binoculars to observe behavior of parturient females and their fawns while causing minimal disturbance to our subjects. We searched for parturient females and observed births and perinatal behavior opportunistically from approximately 7:30 AM to 6:30 PM during four field trips from March to June 2010, March to June 2011, August to November 2011, and June to September 2012. Thomson's gazelle give birth year-round but exhibit birth peaks roughly coinciding with the semiannual rains (Brooks, 1961; HvidebergHansen, 1970; Robinette \& Archer, 1971), which at OPG occur from March to April and October to November. In 2012, OPG had a population of approximately 1300 Thomson's gazelles. Other herbivore species are abundant, as are predators, including lions (Panthera leo), cheetahs (Acinonyx jubatus), black-backed jackals, spotted hyenas (Crocuta crocuta), olive baboons (Papio anubis) and birds of prey.

\section{Observations}

We observed perinatal behavior by locating parturient females or females with neonates that were still wet and unable to walk steadily. Parturient females were easiest to spot when birth membranes were already protruding from the vulva or adhering to the hind legs, but we were also able to identify females in earlier stages of labor by their raised tails, enlarged abdomens, and swollen udders. After finding a female, we observed her for the remainder of the postpartum period, until her fawn began hiding or was killed. We recorded seven observations using a video camera and three using a voice recorder and still photos. One further birth was witnessed and voice-recorded by a colleague.

In addition to narrating the behavior of the female and her fawn, during each observation we noted the time of birth, whether the female was alone or in a social group, and the height of the grass at the birth site. For two of the three observations in which we did not witness parturition, we estimated time of birth based on the fawn's level of development when we encountered it; for observation 10, we could only confidently estimate time of birth to within an hour. Females were considered to be in a group if they were less than $50 \mathrm{~m}$ from their nearest neighbor. We classified the grass 
at the birth site as either short or tall (below and above the hock, respectively).

From the recorded observations, we quantified disturbances to the mother-fawn pair and determined the fawn's conspicuousness. Any separation of the mother and fawn by more than one adult body length resulting from an outside influence or a fear reaction by the mother, but which did not end with fawn predation, was considered a disturbance. Disturbances were caused by male Thomson's gazelles attempting to engage in sexual activity with the mother or neighboring females (three observations); the neonate eliciting fear and flight reactions from the mother (one observation); female Thomson's gazelles enticing the fawn away from its mother or aggressively interacting with the fawn or mother (two observations); Grant's gazelles (Nanger granti; one observation), plains zebras (Equus burchelli; one observation), and female Thomson's gazelles investigating the fawn or birth site (one observation); humans passing near the mother on foot (one observation); and an attack of a fawn by a warthog (Phacochoerus africanus; one observation; Roberts, 2012a). We counted the disturbances for each observation and measured their durations.

We could measure fawn conspicuousness for the video-recorded observations only. We quantified the conspicuousness of the neonate using still frames taken every $60 \mathrm{~s}$ beginning 1 min after birth. For each image we noted whether the fawn was lying down or standing up and estimated the percentage of the fawn that was visible to the nearest $10 \%$. We then compared mean visibility for each fawn position across observations.

\section{Analyses}

We ran all statistical analyses in JMP v10.0. We first used Fisher's exact test, which is valid for small sample sizes, to determine if detection by predators resulted in fawn mortality. We then tested an overall nominal logistic model to determine whether maternal decisions affected the fawns' risk of being detected by predators. We included birth site grass height (short or tall), social context (isolated or not isolated), and the interaction between these two variables as model effects, and used detected (yes or no) as the response variable. We evaluated the model using effect likelihood ratio tests.

After establishing the overall effect of maternal behavior on fawn detection by predators, we went on to examine the underlying mechanisms mediating this effect. We investigated whether prepartum isolation reduced the number of non-predatory disturbances of the mother and fawn, and whether these disturbances prolonged the duration of the postpartum period and thereby increased the fawn's risk of being encountered by a predator. We used Fisher's exact test to determine if prepartum isolation reduced disturbances. To determine the effect of disturbances on the duration of the postpartum period, we first used linear regression to examine the relationship between total disturbance duration and the time it took the fawn to hide (Figure 1). This relationship, although strong $\left(\mathrm{r}^{2}=0.98, \mathrm{p}=\right.$ 0.0002), is based on six observations and driven in part by an outlying data point. Furthermore, in two of these observations, the mother-fawn pairs experienced no disturbances. The dearth of intermediate data points is due to the fact that fawns that are killed never hide; therefore, we have no data on the time delay from birth to hiding for these fawns. In order to include fawns that were killed, we also examined the effect of disturbances on the time it took the fawn to walk. This landmark falls late enough in the fawn's behavioral development that disturbances were likely to happen beforehand, but early enough that most fawns attained the landmark before being killed. Although there were only four observations in which the time delays to both walking and hiding were recorded, these points had a high correlation coefficient $(r=0.83)$. Given this apparent rela- 


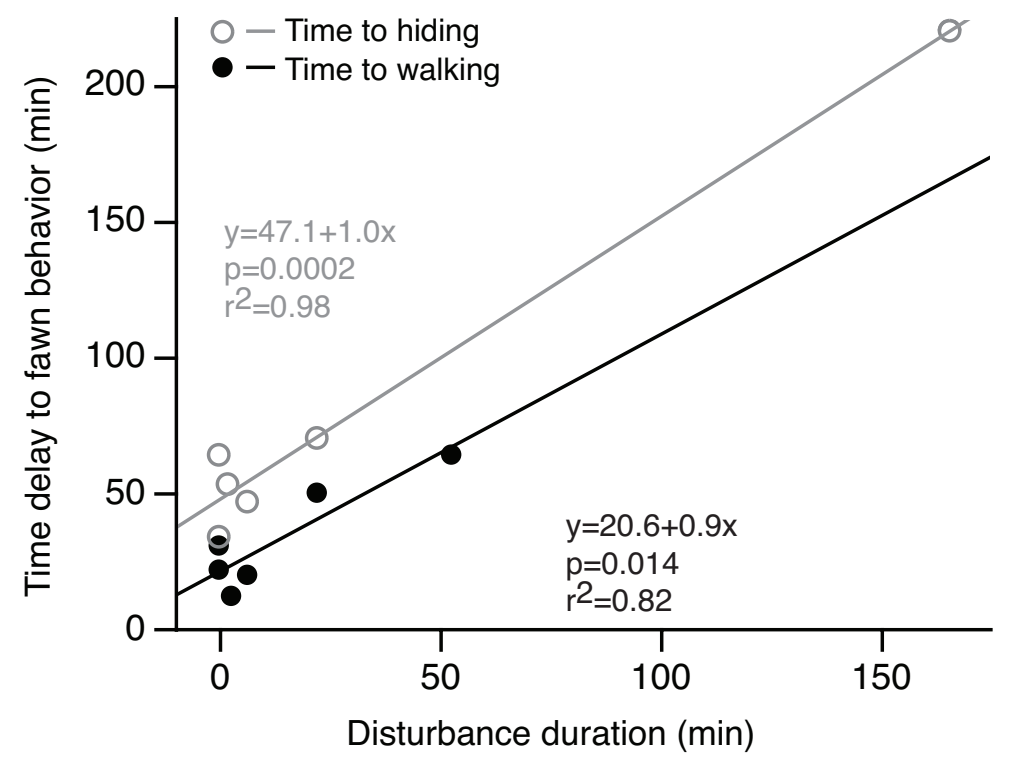

Figure 1. The effect of non-predatory disturbances on the time delay from birth to the onset of hiding (open circles, grey line) and the fawn's first walking bout (closed circles, black line). Fawns that spend more time separated from their mothers due to disturbances during the postpartum period take longer to walk and hide.

tionship and because walking is a prerequisite for hiding, we proceeded under the assumption that fawns that take longer to walk will also take longer to hide.

We constructed two Kaplan-Meier survival curves to examine the effect of postpartum period duration on risk of a predator encounter. One curve modeled the risk of encounter by conventional predators and the other modeled the risk of encounter by all predators. The first curve was constructed using encounter times for fawns that were encountered by jackals, with encounter times by other predators and hiding times included as censored values. In the second curve, all encounter times were used regardless of predator, with hiding times included as censored values. The hiding time for observation 1 was not included in either curve since this fawn was encountered by a predator before hiding and its encounter time is included in the model. We fit log-normal curves to the Kaplan-Meier curves and plotted these on a semi-log plot. The use of the logarithimic scale on the y-axis allows better visual- ization of encounter probability: in this format, lines with constant slope represent constant probability of predator encounter (Deevey, 1947). We used the log-normal curves to determine the survival probability for observed postpartum period durations and to predict the postpartum period durations necessary to yield a variety of survival probabilities.

We also examined whether birth site grass height affected fawn visibility. The ShapiroWilk $W$-test showed our data to be non-normal. Therefore, we used the Mann-Whitney $U$-test, which is appropriate for nonparametric data, to compare fawn visibility between different grass heights across video-recorded observations.

All Fisher's exact tests were two-tailed, and significance in all tests was accepted at $p$ $<0.05$. Because samples sizes are necessarily small, we identify 'strong trends' when $p<0.1$. We do so hoping that such trends will stimulate further studies. In JMP, the Mann-Whitney $U$-test is performed using the Wilcoxon test command, and the Z-statistic rather than the 
$U$-statistic is reported. Therefore, we report our results using the Z-statistics and Wilcoxon test format.

\section{Results}

In more than 13 months of studying maternal behavior in Thomson's gazelles, we observed eleven instances of perinatal behavior. Eight observations included parturition and prepartum behavior, and three began veryshortly after parturition when the fawn was still wet and unable to walk steadily. All fawns exhibited similar levels of movement and vigor after birth and there was no indication that any were born debilitated. Table 1 provides data from each of our observations including time of birth, use of antipredator tactics, and the fate of the neonates.

Mothers in our study did appear to actively choose the circumstances of parturition rather than simply giving birth wherever they happened to be when labor began. We detected signs of labor as early as 90 min prior to parturition and females did not settle at the birth site until between 8 and 43 min prior to parturition. In the interim, we observed some subjects leave their groups and travel (in one case more than a kilometer) from their original position, sometimes moving through multiple grass heights and joining and leaving multiple groups. All females had access to both tall and short grass habitats on the plains on which they gave birth. Females that sought isolation invested considerable effort in shedding herding males and females that followed them away from groups. In two cases the female's decision to isolate or remain in the group was negated when the group rejoined or moved away from her after she became immobile during labor. In both of these instances, the fawn was killed by jackals.

Fawns were attacked by black-backed jackals and warthogs. Females did not appear to regard warthogs as predators. Mothers reacted to jackals and other conventional fawn predators with high levels of vigilance, whereas warthogs were often interspersed in gazelle groups and were ignored until they displaced the mother. During jackal attacks, mothers became alert and fled the birth site as soon as they detected the predator. In contrast, in warthog attacks, the mother continued caring for the fawn until the warthog approached to within a body length (Roberts, 2012a). The differences in maternal reactions to warthogs and jackals suggest that warthogs are an emerging predator at our field site.

\section{Effect of detection by predators on fawn survival}

Six $(55 \%)$ fawns were detected by predators during the postpartum period. Three of these were found by black-backed jackals and killed. Three were found by warthogs, an emerging predator at our field site (see Discussion). Of these, two were killed and eaten and one was attacked but survived (see Roberts, 2012a). A predator encounter during the postpartum period thus drastically decreased a fawn's chance of surviving (Fisher's exact test; $p=0.015$ ). Therefore, in order to improve fawn survival probability maternal antipredator tactics needed to reduce the risk of neonate detection by predators.

\section{Prepartum isolation, birth site grass height, and their effect on detection of the fawn by predators}

Four $(36 \%)$ females were isolated at birth while seven gave birth within $50 \mathrm{~m}$ of at least one conspecific. Of the four females that were isolated at parturition, three $(75 \%)$ gave birth in tall grass, while five $(71 \%)$ of the seven females that remained in their groups gave birth in short grass.

Our nominal logistic model reveals that neither prepartum isolation (effect likelihood ratio test; $\left.\chi^{2}=1.81 \times 10^{-9}, p=1.00\right)$ nor grass height $\left(\chi^{2}=1.93 \times 10^{-9}, p=1.00\right)$ affected whether a fawn was detected by predators. When we 


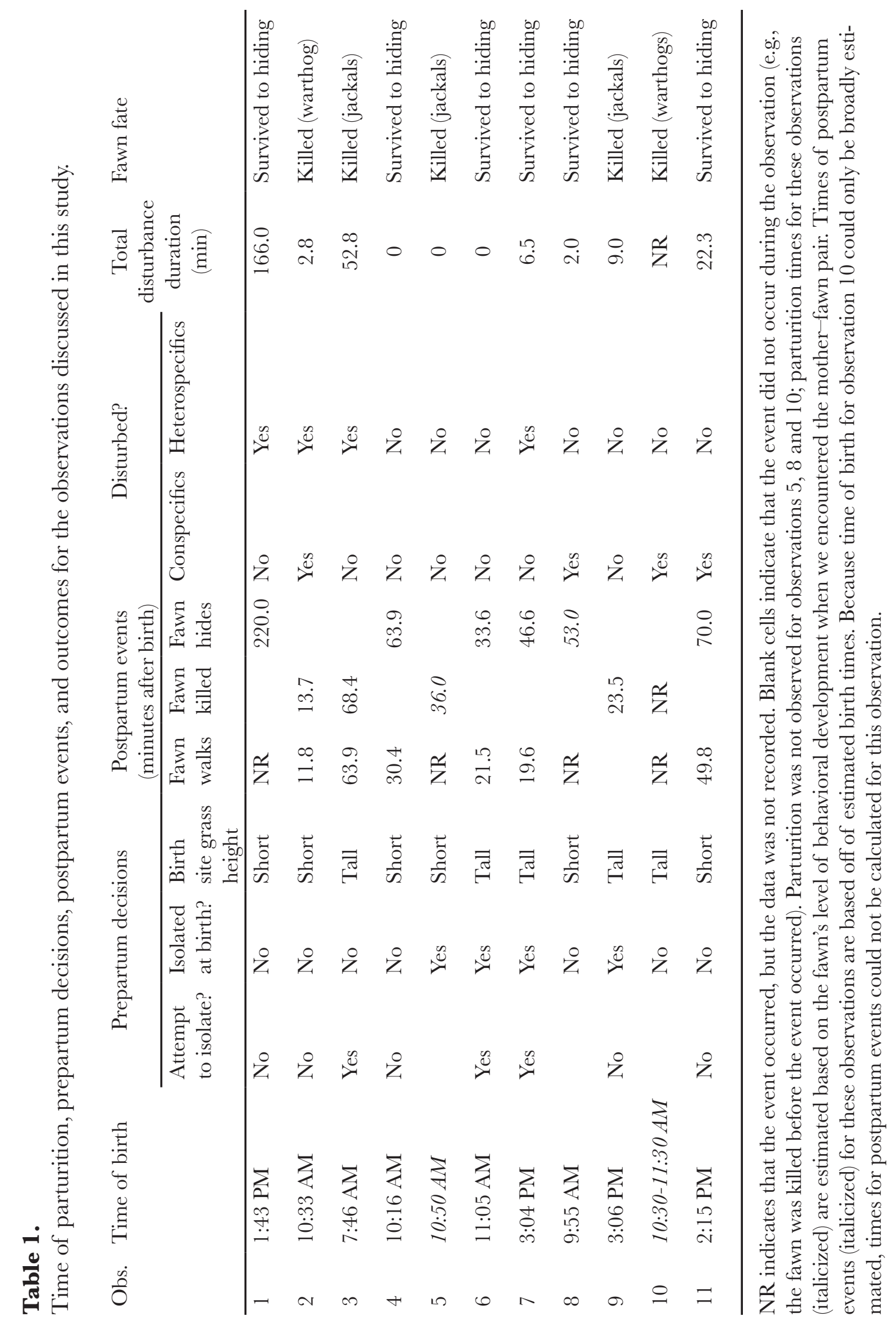

Behavior (2014) vol 151:1229-1248 


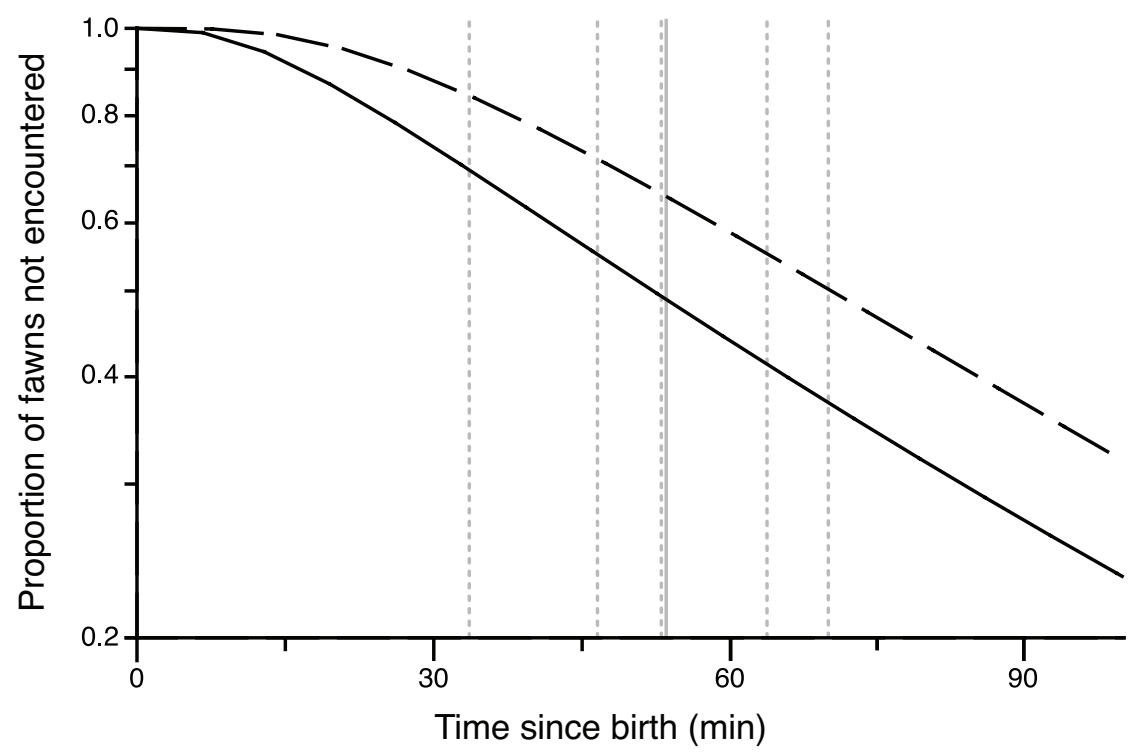

Figure 2. Probability of avoiding a predator encounter during postpartum periods of various durations. We generated the lognormal curves by fitting them to Kaplan-Meier survival curves based on our data. The dashed curve includes only jackal encounters and the solid curve includes all predators. Vertical lines represent hiding times (dotted line) for our observations and the mean hiding time (solid line). The logarithmic scale on the y-axis allows for clearer visualization of encounter probability, with straight lines representing constant risk of encounter (1947).

considered only detection by jackals, there was a strong trend for isolation to reduce the probability of detection $\left(\chi^{2}=3.02, p=0.08\right)$, and grass height had no effect $\left(\chi^{2}=5.88 \times 10^{-9}, p=1.00\right)$. However, the interaction between these two factors had a significant effect on fawn detection by all predators $\left(\chi^{2}=4.32, p=0.038\right)$ and by jackals $\left(\chi^{2}=5.57, p=0.033\right)$. Fawns born either in isolation and in tall grass or in groups and in short grass had a lower probability of predator detection than fawns born under other conditions. Predators detected only one out of three $(33 \%)$ fawns born in isolation and in tall grass and only two out of five $(40 \%)$ fawns born in groups and in short grass. In contrast, all fawns born either in isolation and in short grass (one fawn) or in groups and in tall grass (two fawns) were detected by predators.

\section{Effect of prepartum isolation on distur- bances and postpartum period duration}

Non-predatory disturbances of the motherfawn pair by conspecifics and heterospecifics during the postpartum period were common and occurred in seven of our eleven observations (Table 1). Non-predators disturbed only one $(25 \%)$ of the females that isolated for birth, but six $(86 \%)$ that did not isolate. Although the difference was not significant, there was a trend for mothers that isolated to experience fewer non-predatory disturbances than non-isolated mothers (Fisher's exact test; $p=0.088$ ). When we considered only disturbances caused by other Thomson's gazelles, no isolated females were disturbed by conspecifics, while four $(57 \%)$ females that did not isolate were disturbed by conspecifics. However, this difference was not significant (Fisher's exact test $p=0.19$ ). Figure 1 shows the effect of the total duration of disturbances on the time delay from birth until the fawn hid and time delay from birth until the fawn walked. The more time the mother spent displaced from the fawn during the postpartum period, the longer it took for the fawn to walk and hide. Thus, non-predatory disturbances prolonged the postpartum 


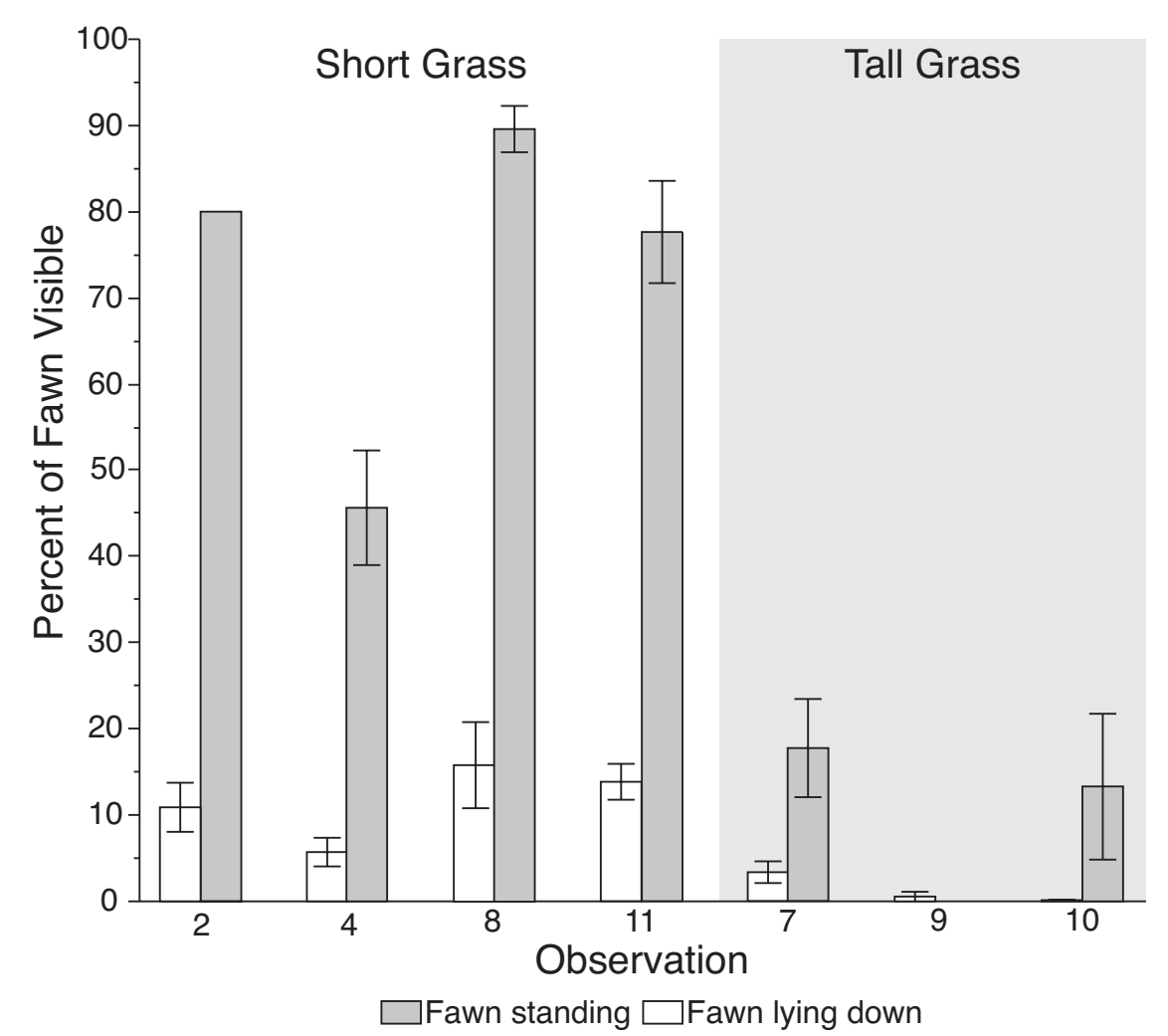

Figure 3. Mean visibility of fawns while standing and lying down in video-recorded observations. Except for observation 4, fawns in short grass are significantly more visible while lying down than fawns in tall grass. All fawns born in short grass are significantly more visible while standing than the fawn in observation 7, which was born in tall grass. Our analysis yielded no data on the visibility while standing of the fawn in observation 9. Error bars indicate standard error.

period. Our survival analysis revealed that risk of a predator encounter was relatively constant during the postpartum period (Figure 2). Therefore, longer postpartum periods incurred greater risk of encounter by predators. The shortest postpartum periods in our observations were exhib-ited by fawns born in isolation (Table 1). These postpartum period durations of 33.6 and $46.6 \mathrm{~min}$ corresponded to survival probabilities of 0.84 and 0.71 , respectively, when only jackals were considered and 0.69 and 0.55 , respectively, when all predators were considered. In contrast, postpartum period durations for fawns born in groups ranged from 53 to $70 \mathrm{~min}$, with survival probabilities of between 0.50 and 0.65 when only jackals were considered and between 0.37 and 0.49 when all predators were considered.

\section{Effect of birth site grass height on fawn visibility and probability of detection by predators}

The mothers and fawns remained at or near the birth site for the majority of the postpartum period; therefore, fawn visibility was largely determined by grass height at the birth site. Figure 3 shows the mean percentage of the fawn's body that was visible when it was standing up and lying down for all video-taped observations. Birth occurred in short grass in observations 2, 4, 8 and 11 and in tall grass in observations 7, 9 and 10. Except for the fawn in observation 4, all fawns born in short grass were significantly more visible when lying down than the fawns born in tall grass. All fawns born in short grass were also significantly more visible when standing than the fawns in 
Table 2. Results of Wilcoxon tests comparing mean fawn visibility when lying down and standing up across video-recorded observations.

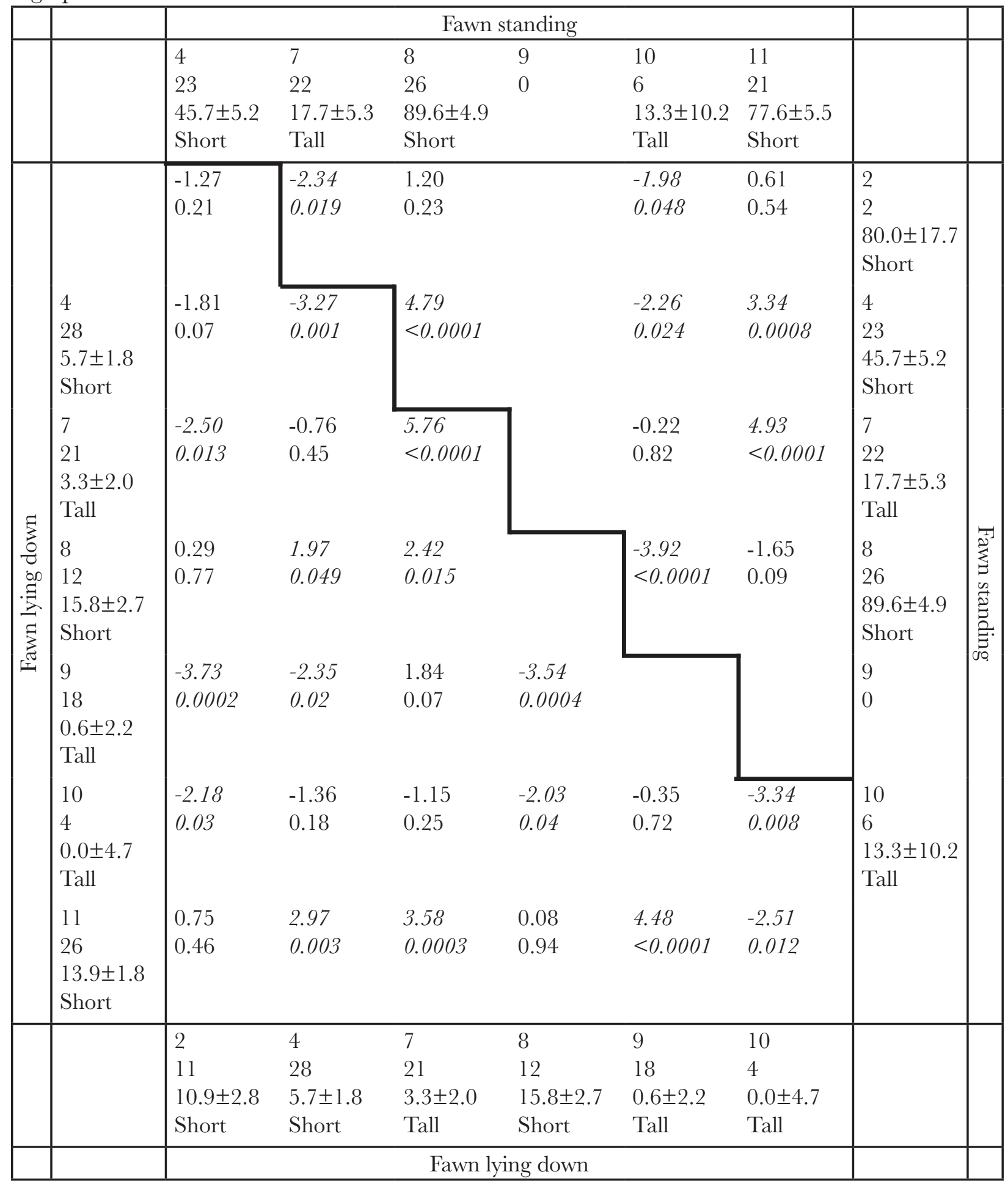

Comparisons for standing fawns are in the upper right portion of the table and comparisons for lying fawns are in the lower left portion. Results cells contain the Z-score followed by the p-value. Values in cells comparing significantly different pairs are italicized. The column headers denote (top to bottom): observation number, number of animals observed, percent of fawn visible (mean $\pm \mathrm{SE}$ ) and grass height (short or tall). 
observations 7 and 10. Our analysis yielded no standing data points for observation 9 . The $Z$-scores and $p$-values for the Wilcoxon tests comparing these means are given in Table 2. Birth site grass height determined fawn visibility. However, the previously described nominal logistic model showed no effect of grass height on a fawn's probability of detection, indicating that fawn visibility does not affect detection.

\section{Discussion}

The postpartum period is a time of potentially high predation risk for ungulate neonates: more than half of Thomson's gazelle fawns in our study were encountered by predators during this time and encountered fawns were almost universally killed. The powerful effect of infant mortality on ungulate population dynamics is well-documented (Gaillard et al., 1998; Gaillard et al., 2000; Raithel et al., 2007). However, the postpartum period is not usually included in studies of infant mortality (Smith \& Anderson, 1996; Singer et al., 1997; Janermo et al., 2004; Olson et al., 2005; DeVivo et al., 2011; Buuveibaatar et al., 2013), suggesting that most studies underestimate infant mortality and predation risk.

Just as in Lott \& Galland's (1985) study on bison, Thomson's gazelle mothers exhibit two primary perinatal tactics, either isolating and giving birth in areas of vegetative cover or remaining in their social groups and giving birth in open habitat. These combinations of social context and habitat type result in fawn survival probability of approximately $65 \%$ and are thus more successful at mitigating fawn predation risk than other combinations, in which all observed fawns were killed. Prepartum isolation and birth site selection thus combine to form behavioral suites rather than functioning independently to reduce fawn risk.

Although it is clear that females actively choose the social and environmental context under which they give birth, the factors leading to the choice of one tactic over another are unknown and require further investigation. Unlike in Lott \& Galland's (1985) study, our females were not subject to obvious differences in habitat availability. Females' decisions may be influenced by habitat variables that we did not detect or on other unknown factors, such as the female's parity or social rank, the composition of available groups, or recent predator activity in the area. In choosing the context of parturition, females may also consider factors beyond offspring survival, such as their own level of predation risk. Due to the energetic expenditure and temporary immobility inherent to labor, mothers are also at heightened risk during the postpartum period and may be safer in groups where risk is diluted or in short grass habitats where predators can be spotted more easily (Fitzgibbon, 1988, 1990). Unlike for some species (e.g., elk, Cerous canadensis; Rearden et al., 2011), we do not expect forage availability to play a large role in birth habitat selection. Gazelle in our system chose birth habitats at a small scale, selecting patches of tall or short grass within their resident plain rather than leaving their normal home range all together. At this scale, after the postpartum period mothers can leave the microhabitat in which they gave birth and select optimal foraging locations nearby while still maintaining typical distances of 50 to $400 \mathrm{~m}$ (Roberts \& Rubenstein, data not shown) from their hiding fawns. Furthermore, mothers essentially cease foraging behavior at the onset of heavy labor and resume feeding when they leave the birth site after the postpartum period.

The two tactics seem to represent a trade-off between reducing the duration of the postpartum period and reducing conspicuousness to predators (Figure 4). Due to our small sample size, we were unable to demonstrate statistically that isolation reduces non-predatory disturbances; however, trends in our data suggest that future studies may establish such an effect. Fewer disturbances result in shorter postpartum periods and lower risk of fawn 


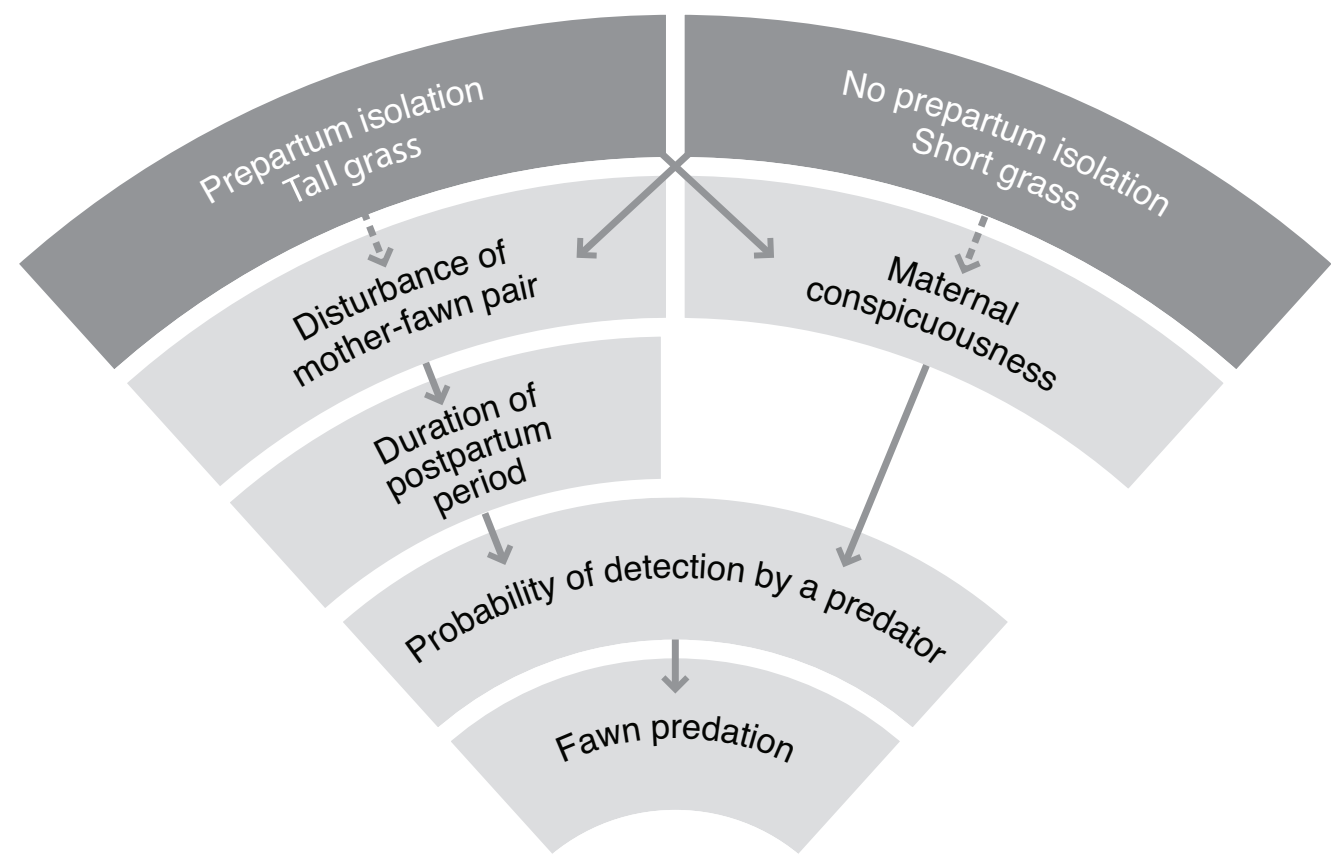

Figure 4. Two main behavioral tactics used by Thomson's gazelle mothers. Solid and dashed arrows represent positive and negative correlations, respectively. Giving birth in isolation and in tall grass serves to minimize non-predatory disturbances and thereby shorten the postpartum period. However, mothers using this tactic are conspicuous to predators. Giving birth within social groups and in short grass serves to minimize maternal conspicuousness to predators, but these mother-fawn pairs are at higher risk of disturbance from conspecifics.

detection. However, our observations of jackal hunting behavior suggest that isolation and use of tall grass habitats may make mothers more conspicuous to jackals. Indeed, the three mothers who lost their fawns to jackals were either alone, in tall grass, or both. Further study of jackal search strategies is necessary to determine how these maternal behaviors may affect neonate risk.

Fawns born in groups may be less conspicuous to jackals than fawns born in tall grass due to social concealment of the fawn and its mother. Indeed, the two fawns born in groups and in short grass that were detected by predators were detected by warthogs. Antipredator behavior is not expected to have evolved to counter warthog predation since gazelle do not regard this species as a predator. In fact, to our knowledge this study is the first recorded instance of warthogs preying on ungulate fawns. Warthogs are known to consume carrion and small vertebrates (Cumming, 1975), and other suids, such wild boar (Sus scrofa; Pavlov \& Hone, 1982; Choquenot et al., 1997; Wilcox 37\& Van Vuren, 2009), hunt and eat juvenile ungulates with some regularity. Similar to wild boar, warthogs catch fawns by knocking them to the ground with their snouts and then eat them while holding them down with a forehoof. Fawn agility increases rapidly in the first hours of life; therefore the window available to warthogs for fawn predation may be limited to the postpartum period.

Given that fawns born in groups and in short grass suffered no jackal attacks, and given that we have already ruled out the possibility of mothers accounting for risk of warthog predation, why do any mothers choose to give birth in isolation or in tall grass? In addition to minimizing the duration of the postpartum period, avoiding non-predatory disturbances may reduce the risk of fawn injury or accidental 
adoption (Lent, 1974; Jarman, 1976; Estes \& Estes, 1979; Guinness et al., 1979). Fawns born in groups were often knocked over by males attempting to court the mother or temporarily 'stolen' by conspecific females. If other neonates are present in the group, the mother may also be at risk of adopting an unrelated fawn at the expense of her actual offspring. Separating from conspecifics and using tall grass as a visual barrier may therefore be an advantageous option during birth peaks or for subordinate individuals that may not be able to effectively deter conspecifics.

This study suggests that further investigation of the understudied postpartum period may yield interesting information regarding maternal risk management and decision-making. Further research involving more individuals are necessary to fully understand factors driving maternal behavior patterns during the postpartum period. Future studies should attempt to include observations of nocturnal and crepuscular births as well as diurnal births. Our observation schedule did not allow us to investigate the effects of time of birth on maternal behavior, but differences in predator activity level and the visibility of mothers and fawns at night may affect maternal behavior and offspring survival.

\section{Acknowledgements}

We thank Ol Pejeta Conservancy for permitting us to work on the premises and the Conservancy's Research Department and security staff for their assistance in the field. We are grateful to Jennifer Schieltz for the use of her recorded observation and to Ipek Kulahci, Molly Schumer, Adrienne Tecza and Chaitanya Yarlagadda for their feedback during manuscript preparation. We thank Mike Costelloe for assistance in figure preparation, especially for the design of Figure 4. This research was conducted with permission of the Government of Kenya (permit NCST/5/002/R/648). Funding was provided by Princeton Univer- sity's Department of Ecology and Evolutionary Biology, the Philadelphia chapter of the Explorers Club, and the Animal Behavior Society's student research grant program. D.I.R. was supported by NSF grants IBN-9874523, CNS-025214 and IOB-9874523.

\section{References}

Alados, C.L. \& Escos, J. (1988). Parturition dates and mother-kid behavior in Spanish ibex (Capra pyrenaica) in Spain. - J. Mammal. 69: 172-175.

Bergerud, A.T., Butler, H.E. \& Miller, D.R. (1984). Antipredator tactics of calving caribou: dispersion in mountains. - Can. J. Zool. 62: 15661575.

Brooks, A.C. (1961). A study of the Thomson's gazelle (Gazella thomsoni gunther) in Tanganyika. Colon Res. Pub. 25.

Buuveibaatar, B., Young, J.K., Berger, J., Fine, A.E., Lkhagvasuren, B., Zahler, P. \& Fuller, T.K. (2013). Factors affecting survival and cause-specific mortality of saiga calves in Mongolia. - J. Mammal. 94: 127-136.

Byers, J.A. (1997). American pronghorn: social adaptations and the ghosts of predators past. University of Chicago Press, Chicago, IL.

Caughley, G. (1966). Mortality patterns in mammals. - Ecology 47: 906-918. 21

Choquenot, D., Lukins, B. \& Curran, G. (1997). Assessing lamb predation by feral pigs in Australia's semi-arid rangelands. - J. Appl. Ecol. 34: 1445-1454.

Cumming, D.H.M. (1975). A field study of the ecology and behaviour of warthog. - Mus. Mem. Natl. Mus. Monum. Rhod. 7: 1-179.

Deevey, E.S. (1947). Life tables for natural populations of animals. - Q. Rev. Biol. 22: 283-314.

DeVivo, M.T., Cottrell, W.O., Deberti, J.M., Duchamp, J.E., Heffernan, L.M., Kougher, J.D. \& Larkin, J.L. (2011). Survival and cause-specific mortality of elk Cervus canadensis calves in a predator rich environment. - Wildl. Biol. 17: 156-165.

Estes, R.D. \& Estes, R.K. (1979). The birth and survival of wildebeest calves. - Z. Tierpsychol. 50: 45-95.

Festa-Bianchet, M. (1988). Seasonal range selection in bighorn sheep: conflicts between forage 
quality, forage quantity, and predator avoidance. - Oecologia 75: 580-586.

Fitzgibbon, G.D. (1988). The antipredator behaviour of Thomson's gazelles. - Dissertation, University of Cambridge, Cambridge.

Fitzgibbon, C.D. (1990). Why do hunting cheetahs prefer male gazelles? - Anim. Behav. 40: 837845.

Fitzgibbon, C.D. (1993). Antipredator strategies of female Thomson's gazelles with hidden fawns. - J. Mammal. 74: 758-762.

Fraser, A.F. (1968). Reproductive behavior in ungulates. - Academic Press, London.

Gaillard, J.-M., Festa-Bianchet, M. \& Yoccoz, N.G. (1998). Population dynamics of large herbivores: variable recruitment with constant adult survival. - Trends Ecol. Evol. 13: 58-63.

Gaillard, J.-M., Festa-Bianchet, M., Yoccoz, N.G., Loison, A. \& Toïgo, C. (2000). Temporal variation in fitness components and population dynamics of large herbivores. - Annu.Rev. Ecol. Syst. 31: 267-393.

Gosling, L.M. (1969). Parturition and related behaviour in Coke's hartebeest, Alcelaphus buselaphus cokei Günther. - J. Reprod. Fertil. 6: 265-286.

Guinness, F.E., Hall, M.J. \& Cockerill, R.A. (1979). Mother-offspring association in red deer (Cervus elaphus L.) on Rhum. - Anim. Behav. 27: 536544.

Hvideberg-Hansen, H. (1970). Contribution to the knowledge of the reproductive physiology of the Thomson's gazelle (Gazella thomsoni Günther). Mammalia 34: 551-563.

Janermo, A., Liberg, O., Lockowandt, S., Olsson, A. \& Wahlström, K. (2004). Predation by red fox on European roe deer fawns in relation to age, sex and birthdate. - Can. J. Zool. 82: 416-422.

Jarman, M.V. (1976). Impala social behaviour: birth behaviour. - East Afr. Wildl. J. 14: 153-167.

Lent, P.C. (1974). Mother-infant relationships in ungulates. - In: The behaviour of ungulates and its relation to management (Geist, V. \& Walther, F., eds). IUCN, Morges, p. 14-55.

Leuthold, W. (1977). African ungulates: a comparative review of their ethology and behavioral ecology. - Springer, Berlin.

Linnell, J.D.C., Aanes, R. \& Andersen, R. (1995). Who killed Bambi? The role of predation in the neonatal mortality of temperate ungulates. -
Wildl. Biol. 1: 209-223.

Lott, D.F. \& Galland, J.G. (1985). Parturition in American bison: precocity and systematic variation in cow isolation. - Z . Tierpsychol. 69: 66-71.

Olson, K.A., Fuller, T.K., Schaller, G.B., Lhagvasuren, B. \& Odonkhuu, D. (2005). Reproduction, neonatal weights, and first-year survival of Mongolian gazelles (Procrapra gutturosa). - $\mathrm{J}$. Zool. 265: 227-233.

Pavlov, P.M. \& Hone, J. (1982). The behaviour of feral pigs, Sus scrofa, in flocks of lambing ewes. Aust. Wildl. Res. 9: 101-109.

Pinard, V., Dussault, C., Ouellet, J.-P., Fortin, D. \& Courtois, R. (2012). Calving rate, calf survival rate, and habitat selection of forest-dwelling caribou in a highly managed landscape. - J. Wildl. Manage. 76: 189-199.

Poole, K.G., Serrouya, R. \& Stuart-Smith, K. (2007). Moose calving strategies in interior montane ecosystems. - J. Mammal. 88: 139-150.

Raithel, J.D., Kauffman, M.J. \& Pletscher, D.H. (2007). Impact of spatial and temporal variation in calf survival on the growth of elk populations. - J. Wildl. Manage. 71: 795- 33803.

Read, B. \& Frueh, R.J. (1980). Management and breeding of Speke's gazelle, Gazella spekei, at the St. Louis Zoo, with a note on artificial insemination. - Int. Zoo Yb. 20: 99-106.

Rearden, S.N., Anthony, R.G. \& Johnson, B.K. (2011). Birth-site selection and predation risk of Rocky Mountain elk. - J. Mammal. 92: 11181126.

Roberts, B.A. (2012a). An attack by a warthog Phacochoerus africanus on a newborn Thomson's gazelle Gazella thomsonii. — Afr. J. Ecol. 50: 507508.

Roberts, B.A. (2012b). Perinatal behavior of a wild Grevy's zebra (Equus grevyi) mare and foal. - J. Ethol. 30: 205-209.

Robinette, W.L. \& Archer, A.L. (1971). Notes on ageing criteria and reproduction of Thomson's gazelle. - East Afr. Wildl. J. 9: 83-98.

Rubenstein, D.I. \& Nuñez, C. (2009). Sociality and reproductive skew in horses and zebras. - In: Reproductive skew in vertebrates: proximate and ultimate causes (Hager, R. \& Jones, C.B., eds). Cambridge University Press, Cambridge, p. 196-226. 
Singer, FJ., Harting, A., Symonds, K.K. \& Coughenour, M.B. (1997). Density dependence, compensation, and environmental effects on elk calf mortality in Yellowstone National Park. - J. Wildl. Manage. 61: 12-25.

Smith, B.L. \& Anderson, S.H. (1996). Patterns of neonatal mortality of elk in northwest Wyoming. - Can. J. Zool. 74: 1229-1237.

Walther, F. (1965). Verhaltensstudien an der Gattung Tragelaphus de Blainville (1816) in Gefangenschaft unter besonderer Berücksichtigung des Sozialverhaltens. - Z. Tierpsychol. 21: 393467.

Wilcox, J.T. \& Van Vuren, D.H. (2009). Wild pigs as predators in oak woodlands of California. - J. Mammal. 90: 114-118. 